\title{
LA HIPÓTESIS NC NOTAS PARA EXPLICAR LA EXPLOSIÓN DE CÁDIZ DE 1947
}

\author{
Miguel Ángel López Moreno \\ Universidad de Cádiz
}

\section{RESUMEN}

En Julio de 1943 llegaron a la Base de Defensas Submarinas de Cádiz cincuenta cargas de profundidad alemanas del modelo WBD. Eran parte del acopio de armas submarinas que el gobierno español usaría para impedir un hipotético desembarco aliado por costas andaluzas. Este trabajo atribuye la Explosión de Cádiz de 1947 a estas cargas WBD que no contenían el explosivo previsible -hexanita o SW18- sino que, sorprendentemente, cargaban algodón pólvora, un explosivo obsoleto que se descompone espontáneamente en una reacción exotérmica y autocatalítica, y llega a provocar la autoignición si se produce en el seno de una masa crítica, máxime si no se conserva en condiciones adecuadas, como fue el caso.

PALABRAS CLAVE: "Explosión de Cádiz", 1947, "algodón pólvora", nitrocelulosa, "cargas de profundidad", WBD.

\section{ABSTRACT}

In July 1943, fifty german depth charges (WBD) arrived to Cádiz (Spain). They would use to repel an hypothetical attack from the Allies (World War II). All this explosives were stored in the city just to 1947, when a big explosion occurred. This study gives a new explanation to the explosion in Cádiz since those bombs did not carry the typical explosive -hexanite or SW18- but their content was guncotton, a very unstable and obsolete explosive which is able to spontaneously descompose itself 
through a exotermic and autocatalytic reaction. If we have a big mass and no good condition to preserve, that reaction can derive in an autoignition.

PALABRAS CLAVE: "Explosion in Cádiz", 1947, guncotton, nitrocellulose, "depth charges", WBD.

\section{ANTECEDENTES}

En el contexto de la Segunda Guerra Mundial, desde septiembre de 1942, en previsión de un hipotético desembarco aliado por el sur de la península ibérica, la Armada Española venía almacenando armas submarinas en las antiguas dependencias de la factoría Echevarrieta y Larrinaga de Cádiz, reconvertida a tal efecto en Base de Defensas Submarinas. La intención de la Armada era acopiar hasta 16.000 minas submarinas con las que minar las zonas costeras -desde Huelva hasta Almería- susceptibles de ser utilizadas como puntos de desembarco aliado en Europa ${ }^{1}$. Finalmente, en Julio de 1943, los aliados desembarcan en Sicilia y el peligro inminente para nuestras costas desaparece. Desde entonces, la necesidad de almacenar armas submarinas en Cádiz no es tan perentoria, pero las autoridades militares no disponen de un lugar adecuado para reubicarlas.

Cuatro años más tarde, el 15 de julio del año 1947, en el recinto militar seguían almacenadas algo más de dos mil doscientas bombas, entre minas submarinas, cargas de profundidad y torpedos. Treinta y tres días después, el 18 de agosto, a las diez menos cuarto de la noche, estalló el almacén $n^{\circ} 1$ de la citada base, junto al barrio de San Severiano. Causó ciento cuarenta y siete muertos, miles de heridos y enormes daños materiales en la ciudad. La investigación oficial no concretó la causa de la explosión:

“...la explosión debió ser provocada por una causa inicial probablemente ajena a los explosivos, aunque no pudiendo asegurarlo por la procedencia extranjera de los mismos" 2 .

En consecuencia, se ha especulado mucho sobre el origen de la tragedia con teorías que se basan en indicios, suposiciones, filtraciones interesadas, condicionantes complejos, etc., cuando no en fantasías indemostrables. La Hipótesis Nc (Teoría de la Nitrocelulosa) explica la explosión a partir de hechos y datos contrastados, y se fundamenta en la inestabilidad química inherente a la nitrocelulosa $(\mathrm{Nc})$, sustancia explosiva presente en cincuenta cargas de profundidad del modelo alemán WBD que se almacenaron en la Base de Defensas Submarinas de Cádiz. La presencia de nitrocelulosa en esas cargas se había ignorado hasta la publicación del libro de J. A. Aparicio.

1 “Anteproyecto de minado de las aguas del Departamento", Legajo 4019 del Archivo Naval de San Fernando (ANSF), en [APARICIO FLORIDO, José Antonio. La noche trágica de Cádiz. Testimonios inéditos de la tragedia de 1947. Cádiz, 2009 / I.S.B.N.: 978-84-92717-00-2].

2 En la Causa Judicial Cádiz 197/1947. 


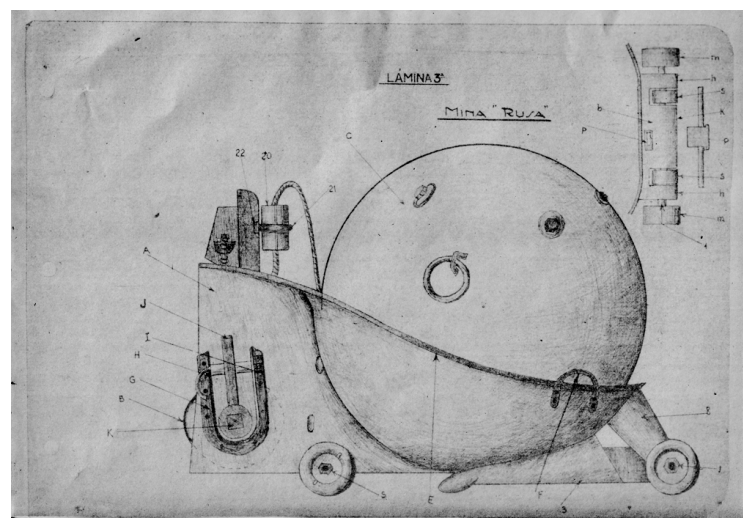

Imagen 1.- Mina rusa. Durante mucho tiempo las minas rusas, por obsoletas y deterioradas, fueron sospechosas de haber provocado la explosión. Es erróneo.

[Biblioteca del Laboratorio de Pólvoras / POLDIZ / B.N. Rota].

\section{PUNTO DE PARTIDA}

Tal vez el dato fundamental que aporta Aparicio son las cantidades, tipos, modelos y disposición física de minas, cargas de profundidad y torpedos presentes en la Base de Defensas Submarinas el 15 de julio de 1947, un mes antes de la tragedia ${ }^{3}$.

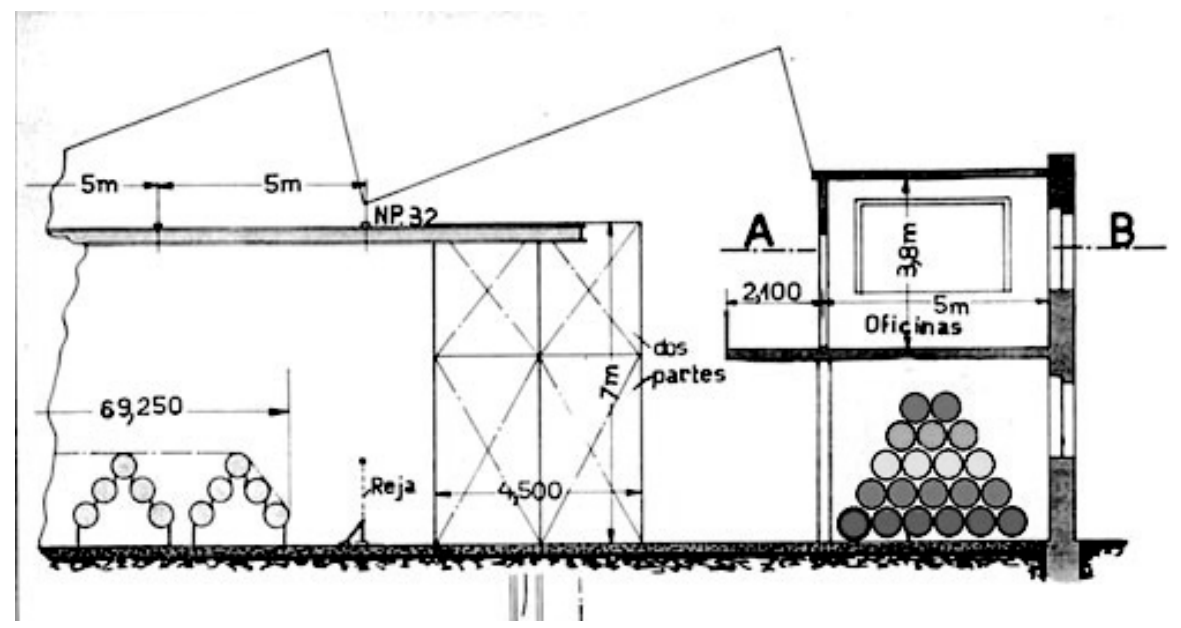

Imagen 2.- Detalle del taller de torpedos Echevarrieta y Larrinaga, reconvertido en Almacén $n^{\circ} 1$, que muestra la estiba de cargas de profundidad bajo la entreplanta.

3 "Memoria correspondiente a los ejercicios y movilización de la Base de Defensas Submarinas de Cádiz durante el periodo de tiempo comprendido entre 15 de abril y 15 de Julio de 1947”. Documento firmado por el C.F. Jefe de los Servicios de torpedos y defensas submarinas, don Miguel Ángel García-Agulló. Cádiz, 15 de Julio de 1947. Archivo Naval de San Fernando (ANSF), legajo 4049, carpeta n ${ }^{\circ} 41$. En [Aparicio, 2009]. 
La explosión se inicia en el Almacén $n^{\circ} 1$-antiguo taller de torpedos de la factoría Echevarrieta y Larrinaga-, concretamente en el lugar donde se estibaron 596 cargas de profundidad de distintos tipos. La localización de la primera explosión no plantea discusiones, tanto la primera inspección dirigida por el juez Mariano de las Mulas Mesones, como la posterior investigación que realizó la Comisión Pericial de la Armada, coinciden en localizarla sobre un enorme socavón (en un suelo de hormigón de treinta centímetros de espesor) de entre diez y catorce metros de diámetro y de uno y medio a dos de profundidad. Justo donde se estibaron las cargas de profundidad. En ese preciso punto ocurrió una explosión cuya onda de choque tuvo que ser necesariamente perpendicular a la superficie del suelo para provocar tal embudo. Inmediatamente después, por simpatía, detonaron minas y torpedos del mismo almacén.

También hay coincidencia en ubicar, muy cerca de las cargas de profundidad, sobre dos habitáculos situados en un piso superior ${ }^{4}$, un número indeterminado de detonadores, multiplicadores y espoletas procedentes de las minas, cargas de profundidad y torpedos ${ }^{5}$. Sin embargo, el grueso de espoletas, detonadores, mechas, fósforos y cargas iniciadoras para las minas y cargas de profundidad depositadas en la Base de Defensas Submarinas, no se hallaban presentes en la explosión: estaban en el Taller de Mixtos de San Fernando, a más de quince kilómetros de distancia en línea recta. Así lo certifica don Leonardo Garófano, oficial de cargo del citado taller, el 4 de septiembre de 1947, en su "Relación del material que había sido recuperado por encontrarse depositado en los Mixtos".

\section{LA IMPROBABLE EXPLOSIÓN INICIAL}

\section{Una caída imposible}

Para explicar la primera explosión no es descaminado pensar en la detonación accidental de algún explosivo sensible, justamente algunos de los que se almacenaban encima de las cargas de profundidad. De hecho, así lo estimó el almirante Estrada, jefe del Departamento, en su informe de agosto/1947 sobre la explosión:

\section{"C.- CAUSAS DE LA EXPLOSIÓN.-}

Es presumible que las causas sean debidas a la explosión de la pirámide de cargas de profundidad producida a su vez por la de los artificios situados en la planta superior. La de estos últimos, por su mayor sensibilidad, puede haberse producido por cualquier circunstancia fortuita”.-

\footnotetext{
4 Ibidem. En el "Informe referente a la catástrofe de Cádiz" presentado por el almirante Estrada, Jefe del Departamento en 1947 (Archivo personal de Miguel García Díaz), se dice: "Directamente encima de la pirámide formada por las cargas de profundidad, y en planta superior, un local en el cual se encontraban almacenados una determinada cantidad, de cebos de fulminato, multiplicadores, y artificios varios".

5 Recordemos que la espoleta es el mecanismo que hace detonar la carga explosiva principal. Las que nos ocupa suelen estar formadas por un detonador de fulminado de mercurio que se inicia por percusión. Esta primera detonación se transmite al multiplicador, formado por pequeño cartucho de tetralita, que a su vez hace detonar la carga iniciadora formada por pastillas de tetralita/trilita. Esta última es la que proporciona la suficiente energía para hacer explotar la carga explosiva principal. Estas espoletas de armas submarinas se almacenan separadas de la carga principal, y, en situación de reposo, el detonador/multiplicador queda separado de la carga iniciadora. Unicamente cuando están montadas en el cuerpo del arma submarina, y sumergidas a suficiente profundidad, entra en contacto el detonador/multiplicador con la carga iniciadora. 6 [Aparicio, 2009]. ANSF, legajo 4019.
} 
Todos los informes y declaraciones que se presentaron o se dijeron en la vista judicial hablan del buen embalaje de las espoletas [primorosamente embalados, se dice textualmente]. Esto implica que cada espoleta se almacenaba embutida en un contenedor diseñado específicamente para amortiguar los efectos de caídas accidentales, y para impedir cualquier desplazamiento, golpe o roce en el interior del mismo.

En todo caso, en este tipo de armas submarinas, el conjunto formado por el detonador de fulminato de mercurio y la carga iniciadora de tetralita/trilita nunca entran en contacto hasta el armado de la espoleta, y eso ocurre sólo cuando la presión del agua es al menos la que se alcanza entre los tres o seis metros de profundidad. Para mayor seguridad, las espoletas almacenadas, en tierra o a bordo, se gradúan para detonar a la máxima profundidad. Esto implica que el detonador-multiplicador y la carga iniciadora quedan físicamente separados y asegurados y, en caso de fractura del seguro, será precisa una altísima presión para que los elementos del tren de encendido entren en contacto. De esta forma, mientras permanezcan separados, la explosión accidental del detonador dentro de una espoleta no armada, no podría proporcionar la suficiente energía para hacer estallar ni siquiera la carga iniciadora ${ }^{7}$.

De los explosivos presentes en las espoletas que nos ocupa, sólo los detonadores de fulminato de mercurio se acercan a la posibilidad de una detonación accidental por percusión -en el supuesto caso de que estuviesen separados del resto del mecanismo de encendido y almacenados sin la debida protección en los habitáculos de la entreplanta-. Otros explosivos presentes, pastillas de tetralita y trilita de cargas iniciadoras y multiplicadores, no son lo suficientemente sensibles al choque o fricción.

La sensibilidad a la percusión de un explosivo se puede determinar dejando caer verticalmente una masa (martillo) de dos kilogramos sobre un detonador metálico estándar que contiene diez gramos del explosivo que se quiere ensayar. El detonador se apoya sobre un yunque. La altura necesaria, desde la que debe caer el martillo, para provocar la explosión, expresada en centímetros, es una medida muy visual de la sensibilidad del explosivo a la percusión. Con la trilita se necesita elevar la masa noventa centímetros; con la tetralita, cuarenta; con el algodón pólvora $(\mathrm{Nc})$, veinte; y con el fulminato de mercurio solamente cuatro. ¿Podría ser este el causante de la explosión inicial? ${ }^{8}$

Sabido este comportamiento no es difícil invertir la situación para imaginar qué pudo pasar el 18 de Agosto de 1947 en ese pequeño almacén. Si tomáramos ese mismo detonador estándar (no muy alejado de los detonadores reales) que contiene diez gramos de fulminato de mercurio, ¿desde qué altura debería caer verticalmente para detonar? Un razonamiento somero nos demuestra que si queremos hacerlo explotar debería alcanzar en el suelo la misma energía cinética que la masa de dos kilos al caer

\footnotetext{
7 [Material de cargas de profundidad. Escuela de Armas Submarinas Armada Española, 1950]. Cargas de profundidad "W.B.D.", "W.B.D. II" y "F”, pp 4-5. “En estas cargas tipo 'D' [WBD] queda excluido en cierto grado el peligro de una avería en el buque, aún estando puesta la carga iniciadora y el dispositivo de encendido con el detonador, pues la explosión anticipada de este no hace efecto sobre la carga en posición de seguro y la anticipada de la carga iniciadora no se extiende a la carga principal, pero sí será ésta destruida completamente, por lo que se colocará la carga iniciadora solamente cuando se vaya a emplear pronto la carga de profundidad.” Pero el manual es aún más explícito en la descripción de la carga, que se diseña para evitar “...que se inicie la carga al explotar inesperadamente la cápsula de fulminato de mercurio”. 8 Los datos de la sensibilidad a la percusión están extraídos de [Explosivos y Municiones. Publicación 340. Escuela Naval Militar de Marín, 1976].Pág. II-6.
} 
desde una altura de cuatro centímetros; y un cálculo rápido nos permite deducir que debe caer desde una altura aproximada de ocho metros. El mismo supuesto detonador cargado con tetralita debería caer desde ochenta para explotar; y otro de trilita, desde ciento ochenta metros.

Sin embargo, la entreplanta donde se dispuso el pequeño almacén de artificios se alzaba a cuatro metros del suelo, y la altura del habitáculo era de 3'8 m. Un hipotético detonador estándar cargado con diez gramos de fulminato de mercurio sólo habría explotado si desciende en caída libre desde el techo del pequeño almacén hasta el suelo de la nave, atravesando limpiamente el piso de la entreplanta. Cosa altamente improbable, además de imposible... máxime si tenemos en cuenta que el peso real de fulminato de mercurio en los detonadores -en las cargas de profundidad- oscila entre los 0,8 gramos en las WBA y los 5 gramos de las Vickers. En estos casos deberían caer respectivamente desde una altura de 99 y 16 metros para hacer explosión.

Concluimos, por tanto, que es extraordinariamente improbable que la explosión inicial se debiera a la caída de algún artificio detonador almacenado en el pequeño almacén de la entreplanta, entre otras cosas porque debería explosionar precisamente en el interior de una masa "suficiente" de alto explosivo para provocar la detonación de la primera carga de profundidad. Conclusión que coincide con la opinión del general don Manuel Vela Bermúdez (presidente de la comisión de investigación que surgió de la Orden Ministerial 449/47, de 14 de Octubre), que sostuvo -en contra de la opinión del almirante Estradaque la hipotética explosión accidental de algún artificio (detonador o multiplicador) no podría hacer detonar la carga principal de ninguna mina, carga o torpedo:

“... aún suponiendo que la explosión de una espoleta pudiera provocar las de una caja, es inaceptable para mí que tal pudiera ser la causa del accidente de Cádiz. Es muy poco peso de explosivo, y está tan fuertemente limitado el efecto de una explosión, por el robusto envase, que no veo causa bastante para producir la detonación que causa en embudo en el terreno"'.

\section{LA ALTA TEMPERATURA AMBIENTAL, TAMPOCO}

Si la hipotética explosión primigenia no pudo deberse a la caída accidental de algún detonador de fulminato de mercurio, ¿podría la relativamente alta temperatura ambiental del Almacén $n^{\circ} 1$ desencadenar una reacción explosiva en cadena?

Cada explosivo tiene una sensibilidad al calor definida como la temperatura en grados centígrados a la cual se inicia la explosión. El material sensible almacenado encima de las cargas de profundidad estaba formado, recordemos, por cápsulas de fulminato de mercurio para los detonadores, y pastillas de tetralita y/o trilita para los multiplicadores y cargas iniciadoras. ¿Pueden estas especies explosivas detonar espontáneamente en las condiciones en las que estaban ese día?

El fulminato de mercurio tiene una temperatura de inflamación -siempre que el calentamiento sea rápido- que oscila entre $187^{\circ}$ y $190^{\circ} \mathrm{C}$. Si bien es cierto que a $50^{\circ}$

9 De la causa judicial Cádiz 197/1947, folio mil nueve. Declaraciones de don Manuel Vela Bermúdez, General Inspector del Cuerpo Facultativo de Armas Navales. 
C comienza a descomponerse, lo hace para perder capacidad de explosión; de forma que si realmente el almacén hubiera alcanzado ese régimen de temperaturas durante un número significativo de días se habría reducido su capacidad explosiva.

La trilita (TNT), es muy resistente al calor, de forma que hasta los $160^{\circ} \mathrm{C}$ no se observa formación de productos gaseosos propios de la descomposición. Detona muy por encima de $\operatorname{los} 260^{\circ} \mathrm{C}$. Incluso los aceites explosivos presentes en el exudado de algunas minas de trilita (mezcla de isómeros mononitrados y dinitrados del tolueno), tienen una alta estabilidad al calor.

Igual pasaría con la tetralita, estable hasta $\operatorname{los} 100^{\circ} \mathrm{C}$, y a partir de esa temperatura se va descomponiendo con la formación de óxidos de nitrógeno y formaldehído. El punto de inflamación lo alcanza a $196^{\circ} \mathrm{C}$.

El ácido pícrico es aún más estable: hay que calentarlo durante media hora a $260^{\circ} \mathrm{C}$ para provocar la explosión. Y el picrato amónico detona entre los 257 y $259^{\circ} \mathrm{C}$ siempre que se caliente a un gradiente de $20^{\circ} \mathrm{C}$ por minuto ${ }^{10}$.

En todos los casos, la temperatura máxima imaginable para el interior del Almacén $n^{\circ}$ 1 en ese día estaría muy lejos de provocar la autoignición del fulminato de mercurio, de trilita, tetralita, ácido pícrico o picratos, tanto contenido en los mecanismos iniciadores como en la carga principal de minas, cargas de profundidad y torpedos.

Concluimos, por tanto, que es extraordinariamente improbable que se pudiera producir una pequeña explosión inicial en el almacén de la entreplanta -ni por ignición espontánea debida al calor, ni por percusión- que se propagara al resto y a las cargas de profundidad situadas inmediatamente debajo.

\section{LA CARGA OCULTA}

El mismo razonamiento anterior habría que aplicar a los explosivos incluidos en minas, torpedos y cargas de profundidad (trilita, mezclas de trilita y otros, y ácido pícrico), que la temperatura ambiental del almacén en un día caluroso de agosto, como única causa, jamás podría hacerlas detonar.

Sin embargo la explosión inicial, la que se propagó al resto de minas y torpedos, ocurrió entre las cargas de profundidad. ¿Por qué? ¿Qué había en esa estiba lo suficientemente peligroso como para provocar la detonación inicial?

La información extraída directamente de manuales de la Armada ${ }^{11}$ indica que el explosivo de esas cargas era trilita fundida, pura o mezclada con otros explosivos, excepto en las cincuenta unidades alemanas del tipo $\mathrm{WBD}^{12}$ que estuvieron depositadas en la Base de Defensas Submarinas de Cádiz desde Julio de 1943.

Estas cargas contenían $125 \mathrm{~kg}$ de algodón pólvora cada una. Este dato, hasta ahora inédito, introduce un parámetro enormemente significativo que no se puede obviar en el intento de explicar el origen de la explosión que nos ocupa.

10 [Manual técnico de explosivos (MTE) T-O-7-5. Ministerio de Defensa. Secretaria General Técnica, 1992]. Fulminato de mercurio en pág. 310. Trilita en pág, 105. Tetralita en pág. 122. Ácido pícrico en pág. 132. 11 [Material de cargas de profundidad. Escuela de Armas Submarinas Armada Española, 1950]. Confirmada en otras dos fuentes: [Apuntes de la Escuela de Armas Submarinas de Soller] y [OBRADOR C.C. Armas antisubmarinas. Escuela de Armas Submarinas 1960].

12 Acrónimo alemán de "Wasser Bombe", modelo D. 
La rendija entre el tubo de la carga iniciadora y el tubo protector va calafateada por un prensaestopas (14).

\section{CARGA PRINCIPAL}

Está constituída por $125 \mathrm{Kgs}$. de algodón pólvora 18, en 18 piezas fabricadas en moldes de fundición y colocadas en dos capas una encima de otra.

En las cargas «D. Il» la carga principal es también de $125 \mathrm{Kgs}$., pero de algodón pólvora 36 ó de trial, y va toda ella fundida dentro de la envuelta.

Para mejor encendido de la carga iniciadora a la carga principal, el tubo (6) va rodeado de una capa de algodón pólvora 18 , fundida en forma de aro, siendo el peso de esta pieza de carga, $14 \mathrm{Kgs}$.

\section{CARGA INICIADORA (Fig. 2 y 3 ).}

Consiste en dos cuerpos de tetralita y uno de trilita con un peso total de 650 grs., suficientemente grande para asegurar la explosión de la carga principal, metidos en un tubo cerrado por sus bases (T), una por una tapa con un embudo alojamiento para detonador y la otra por una

Imagen 3.- Las WBD cargaban $125 \mathrm{Kg}$ de algodón pólvora. Extraído de "Material de Cargas de Profundidad", texto oficial de la Armada Española, 1950. Tres años después de la explosión.

\section{¿POR QUÉ ALGODÓN PÓLVORA?}

El primer diseño de carga de profundidad fue desarrollado por la Royal Navy en 1916, en un tiempo en el que ya estaba en franca regresión el uso de algodón pólvora como explosivo principal en armas submarinas ${ }^{13}$. De hecho a partir de la segunda década del S. XX, todos los países lo sustituyeron por TNT o mezclas de TNT y otros explosivos estables. Tampoco es de extrañar que incluso para un mismo modelo de arma submarina variase el tipo de explosivo en un proceso evolutivo que mejoraba la potencia. Por ejemplo, la carga de profundidad americana Mark VII comenzó usando amatol en 1939 (nitrato amónico y trilita), y acabó cargando torpex en 1942 (Torpedoes Explosive, formado por TNT, RDX y aluminio). Las Wasser Bombe alemanas tuvieron una progresión análoga, las primeras cargaban TNT y/o hexanitas ${ }^{14}$, y las últimas de la

13 [MARTÍNEZ VIVAS, J.; ROJAS FEIGENSPAN, J. y FERNÁNDEZ LADREDA, J. Pólvoras y Explosivos. $3^{\mathrm{a}} \mathrm{Ed}$. Zaragoza, 1920] Pág. 252. “...presumo que la actual contienda europea [se refiere a la Primera Guerra Mundial] es la última que lo emplea [el algodón pólvora] en dicha forma, dado los inconvenientes que presenta". Es la misma información que deja escrita Ortega y Villergas en 1927: "Todas estas buenas propiedades [del TNT] lo hacen muy superior para el servicio de torpedos al algodón pólvora, al que va sustituyendo con ventaja”. [ORTEGA y VILLERGAS, Rafael. Material naval a flote y en tierra. Imprenta del Ministerio de Marina. Madrid, 1927. Pág. 216].

14 En el documento americano [MINE DISPOSAL HANDBOOK / German Depth Charges / March I. 1945] se indica que el explosivo genérico de las cargas alemanas, intervenidas al final de la II Guerra Mundial por el ejército americano, es hexanita (60\% TNT y 40\% hexanitrodifenilamina -HND-, más poderoso que el TNT, desarrollado por Alemania a principios de la II G.M. para paliar la escasez de trilita). 
serie, las WBD, F, G y H usaron hexanitas aluminizadas denominadas SW18 y SW36 ${ }^{15}$. Es decir, no es extraño que el explosivo principal de una carga de profundidad varíe con el tiempo, con las circunstancias logísticas o con los avances tecnológicos de la guerra.

Pero, aún así, durante la II G.M. el uso de algodón pólvora como alto explosivo era totalmente impensable. ¿Por qué entonces las que detonaron en Cádiz, en 1947, contenían algodón pólvora como carga principal?

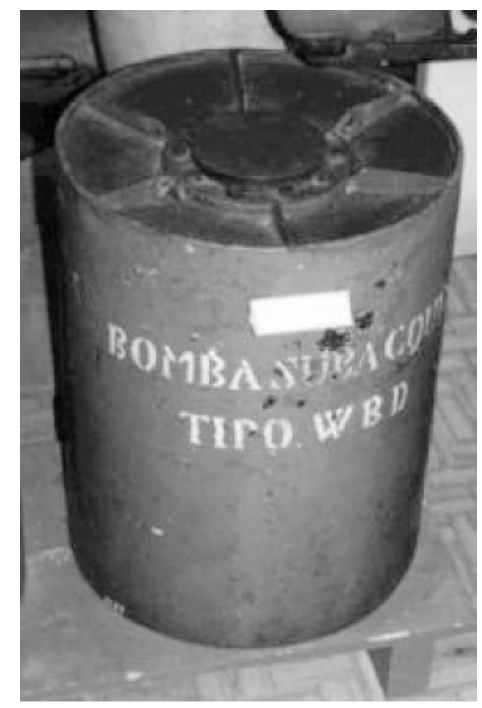

Imagen 4.- German depth charge WBD with $125 \mathrm{Kg}$ of guncotton. "Museo Navale della Spezia, Italy". Cristiano D’Adamo /

Para tratar de explicar esta singularidad nos da una pista la presencia en Italia de las mismas WBD cargadas con algodón pólvora ${ }^{16}$. Efectivamente, en 1942, en plena II Guerra Mundial, Italia no pudo cubrir sus necesidades de armas antisubmarinas con producción propia, y compraron a Alemania, entre otras cosas, precisamente WBD cargadas con algodón pólvora en lugar de la hexanita aluminizada SW18. Esta sustitución del explosivo principal por otro obsoleto debió ocurrir en la inteligencia de que serían armas menos poderosas, más económicas y con una escasa vida útil. Es decir, debían usarse con inmediatez, y nunca almacenarse por tiempo ilimitado $\mathrm{y}$, mucho menos, en malas condiciones ambientales. La coincidencia de fechas -las

15 SW18 es explosivo alemán usado en la II Guerra Mundial. Respecto a las cargas de profundidad WBD, en [CAMPBELL, John. Naval Weapons of World War Two. New York: Naval Institute Press, 1985. ISBN 0-87021-459-4], se indica que estas y las F, G y H contenían explosivo SW18 (SW18: 50\% TNT, 24\% HND, 16\% Aluminio en polvo / SW36: 67\% TNT, 8\% HND, 25\% Aluminio en polvo).

16 Una de esas cargas (con $125 \mathrm{~kg}$ de guncotton) se expone actualmente en Museo Navale della Spezia, Italia. http://www.museotecniconavale.it/vg_sale/index.htm En la descripción de la sala de armas subacuáticas del citado museo se describe textualmente "Una bomba subacquea WBD (n. 6839): caricata con $125 \mathrm{~kg}$. di fulmicotone, aveva 6 regolazioni per lo scoppio a profondità variabili da 20 a 120 m. (2a G.M.)”. 
nuestras llegaron a Cádiz en julio de 1943- nos puede hacer pensar que las italianas y españolas fueran incluso del mismo lote de fabricación. De hecho, es significativo que en 1943, cuando llegaron a la Base de Defensas Submarinas de Cádiz, los informes oficiales de la jefatura decían erróneamente que las 50 cargas WBD eran italianas de la clase torpedini ${ }^{17}$-error que se corrigió en posteriores informes de situación-. ¿Por qué? ¿Procedían directamente del lote que Alemania envió a Italia?

Parece claro que en la traducción de los manuales alemanes al español se sustituyó directamente, sin más consideraciones, los explosivos SW18 Y SW36, por algodón pólvora 18 y 36. Pero la traducción literal y el mantenimiento de los dígitos hicieron este texto incongruente:

"La carga principal de las cargas de profundidad modelo WBD está constituida por $125 \mathrm{Kgs}$. de algodón pólvora 18, en 18 piezas fabricadas en moldes de fundición y colocadas en dos capas una encima de otra. En las cargas "D.II” la carga principal es también de 125 Kgs., pero de algodón pólvora 36 ó de trial [TNT y Aluminio], y va toda ella fundida dentro de la envuelta. Para mejor encendido de la carga iniciadora a la carga principal, el tubo (6) va rodeado de una capa de algodón pólvora 18, fundida en forma de aro, siendo el peso de esta pieza de carga 14 Kgs.”.

En este texto no tiene sentido citar piezas de algodón pólvora fundido puesto que la nitrocelulosa es una fibra vegetal nitrada, que no funde como lo hacen las hexanitas aluminizadas a las que realmente se refiere. Los dígitos 18 y 36 se mantienen como residuos de una traducción incongruente, realizada, sin duda, por un conocedor de las lenguas, pero inexperto en explosivos.

Las WBD que se almacenaron en Cádiz desde el verano de 1943 estaban en buen estado exterior poco antes de la explosión. Y modelos similares (WBD y WBF) siguieron en servicio en la Armada posteriormente aún conociéndose la composición de su carga explosiva.

La información sobre cargas de profundidad está extraída del manual de la Escuela de Armas Submarinas (Armada Española, 1950), editado tres años después de la explosión -y en dos fuentes añadidas-. Y en ellos, en ningún caso, entre las labores de mantenimiento descritos en los Manuales de a Bordo, se indica cómo efectuar una vigilancia que detecte descomposición y/o inestabilidad química del explosivo. Y esto era así porque todas las armas submarinas y municiones tipo bomba que se utilizaron en la Guerra Civil Española, o se adquirieron posteriormente, se las suponía cargadas con TNT o mezclas de TNT y otros explosivos, todos ellos estables. Tanto es así, que desde el punto de vista del mantenimiento son especies químicas de fabricar, cargar y olvidar.

Por desgracia, este concepto de arma con explosivo seguro se aplicó indebidamente a las cargas de profundidad WBD, cargadas con $125 \mathrm{~kg}$ de algodón pólvora. Veamos por qué. 


\section{LA INESTABILIDAD DE LA NITROCELULOSA}

La descubrió accidentalmente el químico suizo-austriaco Christian Schönbein en el año 1847. Se obtiene nitrando celulosa en una mezcla sulfonítrica. El producto así obtenido es una mezcla de nitrocelulosas con distintos grados de nitración. Las que contienen de un 10 a un $12 \%$ de nitrógeno se denominan piroxilinas y se utilizan para la fabricación de pólvora sin humo. Las nitrocelulosas con un contenido en nitrógeno del 12 al 13'5\% se denominan algodón pólvora o fulmicotón, y fue -junto al ácido pícricoel primer alto explosivo usado masivamente en la industria militar.

Pero el producto recién fabricado es tan inestable que, una vez seco, se descompone rápidamente; o se inflama espontáneamente en una estufa. En estas condiciones no tiene utilidad. Es necesario estabilizar la nitrocelulosa mediante la neutralización de todo vestigio ácido. Pero aún así, neutralizada y estabilizada, es un explosivo rompedor muy peligroso, susceptible a detonar al mínimo choque o fricción cuando está seca, tanto más cuanto mayor sea el contenido en nitrógeno ${ }^{18}$. La nitrocelulosa, pese a estar lavada y neutralizada, no es una sustancia estable y se descompone espontáneamente debido a la imposibilidad práctica de eliminar las trazas de impurezas propias de la celulosa de partida.

El proceso de descomposición de las nitrocelulosas de alto contenido en nitrógeno (algodón pólvora y piroxilinas) es inherente a la propia especie química, y se inicia inmediatamente después de su síntesis con la emisión de vapores nitrosos. Es un proceso exotérmico y autocatalítico, es decir, se acelera a sí mismo porque los productos de la descomposición sirven para provocar nuevas reacciones, de forma que si la masa crítica supera un mínimo y está suficientemente aislada térmicamente, acaba por detonar. Estas características de baja estabilidad, alta peligrosidad y fácil deterioro, hizo que muy pronto dejara de utilizarse como explosivo rompedor y se sustituyera por trinitrotolueno (TNT), un explosivo mucho más estable, fiable, duradero y potente.

\section{USO MILITAR DEL ALGODÓN PÓLVORA}

El uso de algodón pólvora como explosivo rompedor se limitó inicialmente a la carga de torpedos y minas submarinas. En estos casos el contenido en agua debía oscilar entre el 15 y el $20 \%$ (pero este porcentaje se elevaba hasta el 25 o el $30 \%$ si se iba a transportar ${ }^{19}$, sólo así, suficientemente húmedo, se podía usar con seguridad). La masa de algodón pólvora convenientemente húmeda y prensada alcanzaba la misma consistencia que la madera, y podía ser aserrada para conseguir la forma requerida como carga explosiva principal.

Paralelamente, el francés Paúl Vielle logró reducir la velocidad de detonación del fulmicotón mediante la gelatinización con alcohol-éter. De esta forma consiguió lo que se denominó pólvora sin humo, un explosivo progresivo que acabó sustituyendo a la tradicional pólvora de salitre, carbón y azufre. En Francia, la pólvora de Vielle se

18 [LÓPEZ MERENCIANO, J. Felipe. Propulsantes de proyectiles y misiles. Ministerio de Defensa, 1991. ISBN: 84-7823-148-X] Pág. 72.

19 [KAST, Hermann y Ludwing METZ. Examen químico de las materias explosivas. Aguilar, 1959] Pág. 389. 
bautizó con el nombre de pólvora Boulanger y desde 1884 se adoptó para los cartuchos reglamentarios del ejército. Sólo dos años más tarde, Alfred Nobel patentó la cordita y la balistita ${ }^{20}$, pólvoras sin humo que se usaron en Italia y otros países desde 1887. La sustitución de la pólvora negra por las nuevas fue un proceso rápido que modificó el planteamiento de las guerras, pero no estuvo exento de resistencia puesto que desde el principio se conocieron los problemas de estabilidad química que presentaba la nitrocelulosa:

"La adopción de la pólvora sin humo se ha hecho en Francia, en Suiza y en Italia, donde se emplea la pólvora Nobel, que es la gelatina explosiva preparada convenientemente; se asegura que la ha adoptado, o está en vísperas de adoptarla, Austria; Alemania la emplea en el cartucho de su nuevo fusil modelo 88, y seguramente en todas partes se estudia y se ensaya; pero es de notar que las pólvoras sin humo adoptadas o en ensayo, todas de constitución química, difieren casi esencialmente unas de otras, y bien se comprende la parsimonia y el detenimiento con que se ha de proceder todo Estado antes de hacer reglamentario para el ejército un nuevo explosivo, cuya permanencia en buenas condiciones, obtenidas quizá en los ensayos, no es posible que pueda desde luego afirmarse sin temor a equivocación, cuando se posee otro de propiedades perfectamente conocidas y comprobadas durante los siglos que lleva en uso" 21 .

Esta desconfianza inicial hacia las nuevas pólvoras estuvo justificada por el enorme gasto que iba a suponer la adaptación del armamento y, por supuesto, al conocimiento cierto de que era una sustancia con caducidad, que perdía condiciones con el tiempo y se hacía tan peligrosa que originaba explosiones inesperadas. Entre otras catástrofes, a la nueva pólvora se le atribuyó la voladura accidental de un polvorín de la Armada Francesa en Lagoubran (Tolón, marzo de 1899): "Se supone que el siniestro no ha obedecido a causa intencionada sino a la descomposición química que haya podido producirse en alguna caja de pólvora sin humo que estalló..."22.

Igualmente, en junio de 1901, "por efecto de reacciones químicas", se inició un incendio en un almacén del depósito naval de la isla de Mare, California ${ }^{23}$. Pero no hay que alejarse mucho, en julio de 1902 explotó uno de los polvorines de la Armada Española situados en Fadricas (San Fernando, Cádiz): "El origen del siniestro se atribuye a la descomposición de la pólvora sin humo, de que había gran cantidad en el polvorín" 24 .

20 La balistita es una mezcla de nitrocelulosa de bajo contenido en nitrógeno y nitroglicerina, estabilizada con vaselina y gelatinizada con acetona. En la cordita se utiliza nitrocelulosa de alto contenido en nitrógeno, nitroglicerina y alcanfor; la mezcla también se gelatiniza con acetona.

21 [MARIANO GALLARDO, Revista Técnica de Infantería y Caballería. 1890. Publicada la reseña en La Ilustración española y americana. Año XXXIV. Núm. 22. Madrid, 15 de Junio de 1890] En Biblioteca Cervantes Virtual.

22 El Imparcial. Madrid. Lunes, 6 de marzo de 1899. Hemeroteca virtual de la Biblioteca Nacional de España.

23 El Imparcial. Madrid. 7 de junio de 1901. Hemeroteca virtual de la Biblioteca Nacional de España.

24 El Imparcial. Madrid. 30 de Julio de 1902. Hemeroteca virtual de la Biblioteca Nacional de España. 
Y ocho años más tarde, en 1909, vuelve a producirse una explosión en los Polvorines de Fadricas, atribuida, asimismo “... a la descomposición de la citada pólvora sin humo, que también había en cajas, almacenadas donde ocurrió la explosión” 25.

En todos estos casos -y en otras catástrofes (acorazados Jena y Liberté, Maine, polvorín de Carabanchel, etc.) en los que no es preciso redundar- la causa apuntada fue la fermentación de la pólvora sin humo, es decir, la inestabilidad química de la nitrocelulosa, componente fundamental de ellas.

Sin embargo las ventajas que presentaba frente a la tradicional pólvora negra fueron innegables, y el proceso de sustitución se llevó a cabo en todos los países, incluido España, en muy pocos años.

Para justificar y documentar los procedimientos de fabricación de la pólvora sin humo, el Ministerio de la Guerra de España comisionó sucesivamente a distintos expertos para que estudiasen estos asuntos en distintos países europeos. En 1894 fueron el teniente coronel don Juan Ruiz Soldado y el capitán don José Calera López ${ }^{26}$. Más adelante fue el químico orgánico de la fábrica de pólvoras El Fargue, de Granada, don Juan Nacle Herrera, para que estudiara la fabricación de la nueva pólvora en Francia, Alemania, Inglaterra y Austria. Esta labor de investigación le fue reconocida oficialmente mediante Real Orden del 17 de agosto de $1897^{27}$. Precisamente, en ese año se inició la producción de pólvora sin humo para fusil en esa fábrica.

Poco tiempo después, mediante R.O. de 2 de Septiembre de 1899, se comisionó al subdirector de esta fábrica granadina, don Ricardo Aranaz e Izaguirre para realizar un estudió pormenorizado no solo de la fabricación de la pólvora sin humo en Europa, sino de los ensayos, análisis y mecanismos de control adoptados para detectar y evitar la inestabilidad de la nitrocelulosa, y aplicarlos en la fábrica de El Fargue ${ }^{28}$. La aplicación en España de esas medidas de control observadas en Europa propició que a partir del año 1900 las pólvoras sin humo fabricadas en el Fargue fuesen más estables:

“...produjeron [las medidas de control] obtener una estabilidad tan grande para las pólvoras, que como resultado de ellas, y no obstante la facilidad de descomposición que les es característica, pueda asegurárseles una vida mucho mayor de 12 años, como lo comprueban las duras pruebas a las que se las somete, y así lo reconoció la $R$. $O$. de 1 de diciembre de 1900 (C. L. número 232), en que adoptaba la denominación de pólvoras de la $2^{a}$ serie para todas las de fusil que tuviesen fabricación posterior a Septiembre de 1900”29.

\footnotetext{
25 La Correspondencia de España. Madrid. 20 de Agosto de 1909. Hemeroteca virtual de la Biblioteca Nacional de España.

26 Real orden concediendo la Cruz de segunda clase del Mérito militar pensionada al Teniente Coronel de Artillería D. Juan Ruiz Soldado, Conde del Peñón de la Vega, por el resultado de su comisión para el estudio de pólvora y cartuchos de fusil; y la Cruz de primera clase de la misma Orden pensionada al Capitán de dicha arma D. José Calera López por su colaboración en los trabajos de la comisión. Gazeta de Madrid núm. 34, de $03 / 02 / 1894$.

27 [RODRÍGUEZ LÓPEZ-NEYRA, C. y CLAVERA ARMENTEROS, J.M. Primer siglo de la facultad de farmacia en Granada. Granada, 1950] Pág. 231.

28 [ARANAZ e IZAGUIRRE, Ricardo. Los Explosivos Militares. Memoria escrita como resultado de la Comisión desempeñada... Granada, 1904] Pág. 11.

29 Ibídem. Pág. 14.
} 
En relación con las pruebas aplicadas al control de las pólvoras, decía Aranaz en su memoria, que las aplicadas en la fábrica de Granada son aún más exigentes que las europeas:

“...y por lo que respecta á la estabilidad, no debo dejar de expresar la impresión relativa á los procedimientos de prueba, tanto con los fulmicotones como con las pólvoras [sin humo]; los cuales, reflejo de los empleados en Inglaterra, no pueden compararse con los duros ensayos implantados por los fabricantes alemanes, que, según tengo manifestado, marchan á la cabeza en este ramo de la industria, cuyos ensayos han sido también aceptados en nuestra fábrica (de Granada), adoptando números todavía más elevados" ${ }^{30}$.

No es preciso insistir más, desde finales del siglo XIX es de dominio público que la nitrocelulosa -con independencia de su uso como explosivo rompedor (algodón pólvora) o en las pólvoras sin humo- debe ser sometida a pruebas y ensayos para determinar su estabilidad química. No es precisamente, por tanto, un explosivo para fabricar, cargar y olvidar. Y aunque esto era perfectamente conocido, el algodón pólvora siguió utilizándose como explosivo rompedor hasta la aparición de la trilita ${ }^{31}$. En 1915 lo expresaban de esta manera Martínez Vivas, Rojas Feigenspán y Fernández Ladreda en el texto sobre explosivos que el ejército usaba en la Academia Militar de Zaragoza ${ }^{32}$ :

"Debe observarse, sin embargo, por lo que respecta al fulmicotón en su calidad de explosivo [rompedor], que en estos treinta y nueve últimos años ha tenido lugar su evolución completa de nacer, vivir y morir, porque presumo que la actual contienda europea [se refiere a la I Guerra Mundial] es la última que lo emplea en dicha forma, dados los inconvenientes que presenta, entre los cuales el principal es su peligroso e inseguro manejo, y dadas también las grandes ventajas del que ya puede decirse que tiene la exclusiva, que es nuestra trilita, o trinitrotolueno por otro nombre, que ha conseguido desbancar al fulmicotón y al ácido pícrico..." ${ }^{33}$.

Por su lado, don Ramón Agacino decía algo muy parecido en el texto oficial de la Escuela Naval Militar (1920), pero enfatizaban el problema de la inestabilidad:

"Por muy bien fabricado que sea este explosivo [se refiere a algodón pólvora], es imposible evitar que, con la acción del tiempo y los agentes

30 Ibídem. Pág. 203.

$31 \mathrm{La}$ trilita se fabrica industrialmente como explosivo desde 1901. [COLVER, W.S. High Explosives. London, 1918] Pág. 20.

32 [MARTÍNEZ VIVAS, J; ROJAS FEIGENSPAN, J y FERNÁNDEZ LADREDA, J. Pólvoras y Explosivos. $3^{\mathrm{a}}$ Ed. Zaragoza, 1920] Obra declarada de texto provisional por R.O. de 14 de Septiembre de 1915 y premiada con la Cruz de $1^{\text {a }}$ clase del Mérito militar con distintivo blanco, pensionada por R.O. de 25 de Enero de 1917.- (D.O. núm. 22). 33 Ibidem. Pág. 252. 
atmosféricos vaya poco a poco descomponiéndose, y que al cabo de algún tiempo, más o menos grande, quede inútil o haga espontáneamente explosión. Tal descomposición tiene poca importancia en tiempo de guerra (y aún en países ricos), pues entre su fabricación y su empleo como explosivo no transcurre tiempo suficiente para que aquella descomposición se manifieste con caracteres alarmantes. Pero en los países pobres, el tiempo transcurrido entre la fabricación y el empleo del explosivo es muy grande y tiene mucha importancia los medios empleados para su conservación" ${ }^{34}$.

Sin duda, palabras proféticas de don Ramón Agacino y Calle, que años más tarde sería el vicealmirante capitán general del Departamento de Cádiz justamente entre 1941 y 1944, periodo en el que arribaron a la Base de Defensas Submarinas las cargas de profundidad WBD.

Prácticamente todos los jefes y oficiales de la Armada, los que ejercían su autoridad en el momento de la Tragedia de Cádiz, tuvieron inevitablemente que estudiar el texto anterior en la Escuela Naval Militar -literalmente ese, extraído del texto oficial, o en todo caso, otro similar- y quiero pensar que si hubieran conocido la existencia de algodón pólvora en las WBD habrían actuado en consecuencia. Pienso sinceramente que ni el almirante Agacino, autor del texto, ni los jefes y oficiales de la Armada de ese tiempo fueron conscientes de lo que contenían estas cargas de profundidad.

\section{CONTROL EXHAUSTIVO DE LA NITROCELULOSA}

Para paliar el peligro que suponía almacenar nitrocelulosa por largo tiempo -tanto en la forma de explosivo rompedor (algodón pólvora) como formando parte de la pólvora sin humo-, las autoridades españolas adoptaron lo que se denominó Reglamento para las Pruebas de Pólvoras y Explosivos que obligaba a una exhaustiva revisión periódica, con pruebas físicas y químicas, de todas estas sustancias. Este primer reglamento se publicó en el Diario Oficial n ${ }^{\circ} 155$ bajo la forma de Real Orden de 13 de Julio de 1904, y se ajustó literalmente a la propuesta presentada por Aranáz e Izaguirre ${ }^{35}$.

Poco después, los militares de la Marina de Guerra acotaron aún más el problema y establecieron unas Instrucciones para el reconocimiento, durante la conservación, del algodón pólvora en las Brigadas Torpedistas que ordenaba una vigilancia muy severa sobre la nitrocelulosa usada hasta entonces como explosivo rompedor ${ }^{36}$. Estas instrucciones detallaban que las municiones que contuviesen algodón pólvora (sería el caso de las WBD) no se podrían aceptar definitivamente hasta que un centro oficial certificara su buen estado. Y una vez almacenadas, debían muestrearse cada tres meses, de forma exhaustiva: “...abriendo toda clase de envase que contenga algodón pólvora”, y extrayendo las muestras de forma que el resultado fuese representativo de todo el lote. A estas muestras tomadas cada trimestre se las sometía a un examen físico y a ensayos

34 [AGACINO, Ramón y GÁMEZ, Joaquín Mª Explosivos. Texto en la Escuela Naval Militar. $2^{\text {a }}$ Edición. Cádiz, 1923] Pág. 267.

35 [ARANAZ e IZAGUIRRE, 1904] Pág. 263 y siguientes.

36 Ibidem. Cap. IX. Pág. 268. 
en laboratorio que incluían pruebas de acidez, estabilidad y explosión. Las muestras de pólvora y algodón pólvora procedentes del sur se remitían al Laboratorio Químico que la Junta Facultativa de Artillería de la Armada tenía en San Fernando, Cádiz. Como resultado de todas estas pruebas, el algodón pólvora debía clasificarse como Excelente, de Servicio, de Consumo Inmediato o Peligroso.

No obstante, a pesar de la inseguridad química de la nitrocelulosa, y su radical abandono como alto explosivo, actualmente se sigue utilizando masivamente en la fabricación de pólvora sin humo, prácticamente el único explosivo propulsor de uso en el planeta ${ }^{37}$. Este hecho implica que todos los ejércitos nacionales, y especialmente los integrados en la OTAN, ejerzan una severa vigilancia, homologada y estandarizada, que incluye revisiones físicas, químicas y balísticas para detectar el mínimo asomo de inestabilidad en todos aquellos artilugios militares que usen nitrocelulosa entre sus componentes. Preocupación que parece sacada literalmente de los criterios que ya se manejaban a principios del siglo XX. La normativa de obligado cumplimiento, tanto nacional como internacional, para la vigilancia de pólvoras de base nitrocelulósica ha seguido vigente desde entonces, y actualmente es muy extensa, detallada, exhaustiva y sujeta a constantes investigaciones y mejoras.

¿Se vigiló de esta forma el algodón pólvora almacenado en la Base de Defensas Submarinas de Cádiz entre 1943 y 1947? Con toda seguridad, no.

En el año 1950, sólo tres años después de la Explosión (a pesar de la vigencia de instrucciones y reglamentos que obligaban a vigilar la estabilidad de las nitrocelulosas), el manual de mantenimiento e instrucción de las cargas de profundidad de servicio en la Armada Española (incluidas las WB alemanas) no contemplaba la vigilancia del explosivo principal aún indicándose expresamente que las D y $\mathrm{F}$ cargaban algodón pólvora. Esta situación vuelve a repetirse años más tarde en el manual de armas antisubmarinas de uso en los años 60, en el que se da a entender que aún siguen en servicio las WBD, pero no se describen. En su lugar se explica ampliamente su gemela de menor tamaño, la WBF, también cargada sorpresivamente con sesenta kilos de algodón pólvora cada una ${ }^{38}$.

Por esa razón aseguramos que las del modelo $\mathrm{D}$, que se almacenaron por tiempo de cuatro años (1943 - 1947) en el Almacén no 1 de la Base de Defensas Submarinas de Cádiz, no estuvieron sometidas a vigilancia química. ¿Por qué esta omisión en los manuales oficiales de algo que siempre ha estado tan severamente cuidado desde principios del siglo XX? De hecho, si dejó de vigilarse la estabilidad del algodón pólvora no fue por falta de medios técnicos para realizar el muestreo y los análisis, puesto que, por esos años, el Laboratorio Químico de la Junta Facultativa de Artillería efectuaba el reconocimiento periódico de todas las pólvoras de base nitrocelulósica de la Armada. Y las pruebas que se efectuaban a las pólvoras sin humo eran y son idénticas a la que se habrían de aplicar al algodón pólvora. Si no se hizo fue por otras causas.

La sustitución de algodón pólvora por trilita -o mezclas de trilita y otros explosivosantes de finalizar la segunda década del siglo pasado fue tan universal, rápida y rotunda que veinte años más tarde, y una Guerra Civil de por medio, las armas antisubmarinas

37 Se utiliza en armas de fuego portátiles, para impulsar pequeños proyectiles, hasta en cañones de grueso calibre. También forma parte de la propulsión de la inmensa mayoría de cohetes y misiles. 38 [OBRADOR C.C. Armas antisubmarinas. Escuela de Armas Submarinas 1960] Cap. V, pág. 1. 
cargadas con algodón pólvora estaban obsoletas, eran historia, puro anacronismo. Y, en todo caso, es un hecho contrastable que desde los años 40 los manuales de armas antisubmarinas son exhaustivos en el mantenimiento y vigilancia de todos y cada uno de los componentes de un arma compleja -como es el caso de minas, torpedos y cargas de profundidad-excepto en lo que atañe a los explosivos (iniciadores y carga principal), que se obvia totalmente. Y eso es así porque tetralita, TNT y sus mezclas, son explosivos tan estables que merecieron la consideración de explosivos para fabricar, cargar y olvidar, y tal seguridad se asumía y se extendía a todas las armas y municiones de ese tiempo. Es decir, las cargas de profundidad WBD, que por una extraña singularidad contenían algodón pólvora -posiblemente una vicisitud logística y económica en mitad de la II Guerra Mundial-, quedaron imbricadas erróneamente en la seguridad genérica que ofrecían todos las municiones y armas de ese momento.

Apoyando esta idea, es muy significativo leer en el manual oficial usado en los años 40 en la escuela de Armas Submarinas de Soller [Material de Minas - Escuela de Armas submarinas] que el algodón pólvora dejó de usarse como carga explosiva por ser menos fuerte y estable que la trilita:

"La carga explosiva [de minas submarinas] deberá estar constituida por un explosivo fuerte y estable y en cantidad suficiente para producir averías en el buque. Del algodón-pólvora que se usaba en un principio se pasó al uso de la trilita, explosivo que llena las necesidades antes citadas...

...últimamente se han usado para la carga explosiva, no solamente la trilita sino otros explosivos más potentes, como el Tri-al empleado por los alemanes y compuesto de trilita, aluminio en polvo $y$ exanitrodifenilamina" 39 .

E igualmente sorprendente es comprobar en el manual oficial de años más tarde [Obrador, 1960], que:

"El explosivo de las cargas generales ha sido normalmente TNT fundida, pero las más modernas se cargan ya con $H B X ” 40$.

Es decir, las cargas con trilita ya dejaban de usarse en las postrimerías de la II Guerra Mundial -con más razones en los años 60-. Sin embargo, en el manual de cargas de profundidad (complementario del de minas) se indicaba que las WBD y WBF cargan respectivamente 125 y $60 \mathrm{Kg}$ de algodón pólvora, explosivo que ya era obsoleto -por peligroso- en la I Guerra Mundial.

39 [Material de minas. Escuela de Armas Submarinas. Armada Española, 1950] Pág. 7. Este manual denomina erróneamente TRIAL a las hexanitas aluminizadas como el SW18. En rigor, trial son mezclas de trilita y aluminio.

$40 \mathrm{HBX}$ son explosivos formados fundamentalmente por mezclas de RDX, TNT, aluminio y ceras. Es una evolución del torpex estadounidense usado en la II G.M. 


\section{UNA FATAL CONTRADICCIÓN}

En Cádiz, entre 1943 y 1947 se produjo una fatal contradicción. Por un lado, los manuales para las cargas de profundidad WBD -que son muy explícitos y detallados en las labores de mantenimiento y manipulación- no alertaban de ningún cuidado especial hacia el explosivo que contenían, simplemente porque todos los explosivos de ese época eran tan estables y seguros que estaban exentos de una vigilancia específica. Este hecho propició sin duda que las WBD, que por una extraña singularidad contenían nitrocelulosa, quedaran imbricadas erróneamente en el concepto de seguridad genérica que tenían todas las municiones en cuanto al explosivo.

Pero, por otro lado, desde principios de siglo existía un Reglamento de Pólvoras y Explosivos que obligaba a analizar y vigilar periódicamente la estabilidad química de todas las nitrocelulosas que la Armada tuviera en servicio.

Y ocurrió que artilleros, condestables y torpedistas - conocedores de todos los detalles de las WBD- no debieron ser conscientes de la peligrosidad de la nitrocelulosa que cargaban... y los técnicos y químicos -al tanto de la inestabilidad de las nitrocelulosas, que las analizaban periódicamente en los distintos laboratorios- no debieron conocer qué explosivo cargaban las WBD. El hecho es que la contradicción no se percibió y no se subsanó. En consecuencia, la inestabilización de la nitrocelulosa era solo cuestión de tiempo...

\section{EL DESENLACE}

El 18 de Agosto de 1947, en el Almacén no 1 de la Base de Defensas Submarinas de Cádiz, se guardaban desde hacía cuatro años 6.250 kilogramos de nitrocelulosa comprimida. Estaban contenidos en cincuenta cargas de profundidad del tipo WBD, llegadas en julio de 1943. Eran parte de una estiba piramidal construida con 596 cargas de profundidad de distintos modelos, en contacto físico unas con otras, que sumaban un total de 33.739 kilogramos de alto explosivo.

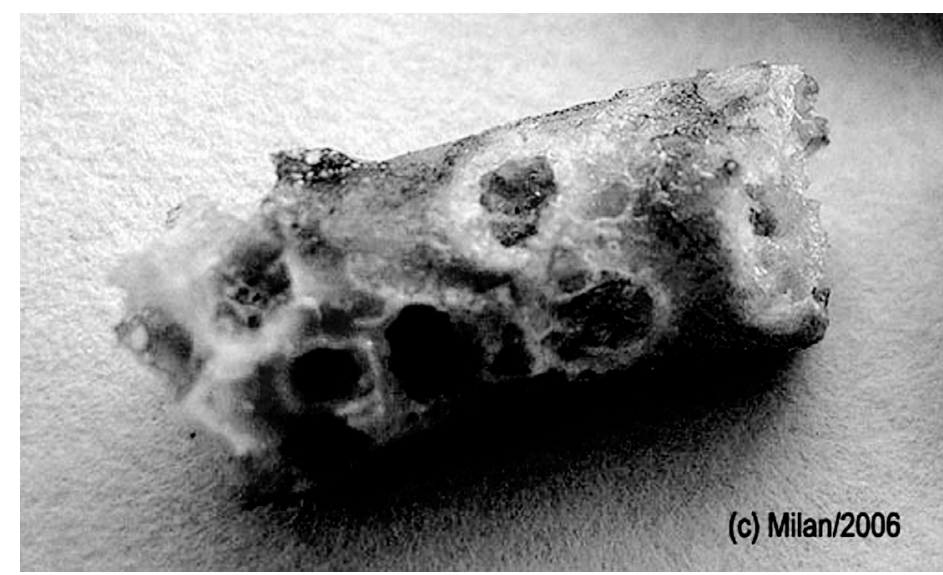

Imagen 5.- Grano de pólvora nitrocelulósica en los primeros momentos de la descomposición. 
Los jefes de la base se venían quejando de la falta de personal y medios para realizar las mínimas labores de mantenimiento de la munición almacenada. Y, en todo caso, aunque hubiesen tenido medios y personal, los manuales de mantenimiento no contemplaban el muestreo y vigilancia del explosivo principal de ninguna de las minas, torpedos y cargas de profundidad.

Estábamos en una dura posguerra. El Almacén $n^{\circ}$, antigua nave-taller de la inacabada Fábrica Nacional de Torpedos, reconvertida en polvorín de fortuna, no disponía de sistema de calefacción para los días fríos, ni refrigeración para días calurosos. Lo cubría un techo de uralita con una superficie superior a 2.900 metros cuadrados, sometida al sol inmisericorde de agosto, capaz de irradiar el interior y calentar el aire en una medida notable; y tenía, además, grandes superficies laterales cubiertas de cristales que provocarían en el interior un efecto invernadero nada despreciable. Es decir, la temperatura constante ideal para conservar la nitrocelulosa, entre 14 y $16^{\circ} \mathrm{C}$, era una entelequia. Al menos, durante los últimos cuatro años, los 6250 kilos de algodón pólvora (desconocemos las vicisitudes anteriores) estuvieron sometidos sin ningún control a picos de temperatura máxima y mínima nada oportunos para su estabilidad química.

Hacía tiempo que comenzó en una de ellas (posiblemente en muchas a la vez) un proceso químico sin vuelta atrás. Las trazas de impurezas en la fibra vegetal que se utilizó para fabricar la nitrocelulosa, los restos ácidos y la alta temperatura del almacén cualquier día de un verano anterior, provocaron la rotura de enlaces y la formación de vapores nitrosos. Estas roturas iniciales desprendieron calor, calentó levemente el entorno y sirvió para aumentar la velocidad del proceso de ruptura; que a su vez desprendió más calor y calentó más intensamente la masa de algodón pólvora. Por su lado los vapores nitrosos catalizaron la propia descomposición, es decir, los grupos nitrosos producidos en las primeras roturas sirvieron para provocar más rupturas de enlaces, que provocaron más grupos nitrosos. Otros de estos grupos se combinaron con el agua presente en el explosivo y regeneraron ácido nítrico y nitroso, que a su vez sirvieron para producir roturas más violentas, y más calor en el seno del explosivo. Todo el proceso se encaminaba poco a poco hacia una reacción en cadena, exotérmica, cada vez más rápida y masiva, sin vuelta atrás; pero las noches y los días fríos jugaban a ralentizar el proceso.

Los días de agosto de 1947 fueron calurosos. Las noches no lograban disipar el calor acumulado durante las horas de sol. Fácilmente en el interior del Almacén $\mathrm{n}^{\mathrm{o}} 1$ se podrían alcanzar los $32^{\circ} \mathrm{C}$. Aunque la nitrocelulosa hubiese estado bien conservada, justo a esa temperatura comenzaría a inestabilizarse con rapidez, pero este no era el caso: llovía sobre mojado, el algodón pólvora ya era extremadamente peligroso. Finalmente a las 21:45 del día 18, la presión de los gases nitrosos retenidos en el interior de una de las cargas WBD fue tal que elevó aún más la temperatura en el interior del explosivo hasta alcanzar el punto de inflamación. La primera carga de profundidad detonó, y desencadenó la explosión simultánea de las demás... siguió el infierno. 